\title{
Mobile Phone Operated Dual-tone-multiple-frequency controlled Microcontroller Based Hockey-ground Rolling Technique
}

\author{
Pratim Banerjee ${ }^{1}$ \\ ${ }^{I}$ (Department of Electronics and Communication, Academy Of Technology, India)
}

\begin{abstract}
Dual-tone-multiple-frequency (DTMF) controlled vehicle is a specific idea in automotive whose actions can be controlled by a mobile phone from all over the world using the DTMF signaling. Traditionally wireless controlled vehicles make use of $R F$ (radio frequency) circuits, which have its own disadvantages of restricted operational range, limited frequency range and limited control. Use of mobile phones for robotic controls provides working range as large as the coverage area of the service provider and no interference with other controllers. I can propose a microcontroller based less effort oriented, cost productive hockey ground roller with smooth pitch rolling technique operated from long range distance by using Mobile phone which acts as a DTMF signal controller with GSM technology. Generally the field of play is 91.4 by 55.0 meters with an area of 5,027 square meters for Hockey. According to my proposed work ground authority can be able to operate that roller to roll aforesaid measurement from pavilion without taking any help of ground staff. Combination of DTMF-GSM technology is more controller friendly as it doesn't interfere with other controllers and can use up to twelve controls. It also has the advantages of robust control and provides working range as large as the coverage area of the service provider.
\end{abstract}

Keywords: Dual-tone-multiple-frequency, radio frequency, roller, GSM

\section{Introduction}

Hockey pitch consists of the central rectangular area inside the boundary with measurement 5,027 square meters. The surface of pitch flattening is necessary. Grounds men can be responsible for rolling the pitch manually, before starting a match. I think that with the help of microcontroller if I propose a system where pitch rolling technique can takes place remotely from long range according to user's demand by using DTMF signaling along with GSM network, it will give a cost effective beneficiary mechanical product in case of hockey pitch preparation. In my proposed work, the roller is controlled by a mobile phone that makes a call to the mobile phone attached to the robot. In the course of a call, if any button is pressed, a tone corresponding to the button pressed is heard at the other end of the call. This tone is called DTMF (dual-tone- multiple-frequency).The roller perceives this DTMF tone with the help of the phone stacked in the roller. The received tone is processed by the microcontroller residing on the Arduino UNO board with the help of DTMF decoder IC (MT8870). The decoder decodes the DTMF tone into its equivalent binary digit and this binary number is sent to the microcontroller. The microcontroller is programmed to take a decision for any given input and outputs its decision to motor drivers in order to drive the motors in forward direction or backward direction or turn. The mobile phone that makes a call to mobile phone stacked in the roller act as a remote. DTMF (Dual tone multi frequency) as the name suggests uses a combination of two sine wave tones to represent a key dialed on a push button or DTMF keypad.

\section{My Proposed Work}

In this paper i can propose a microcontroller based Mobile phone operated user friendly as well as cost productive hockey ground roller with an effective 360 degree rolling technique operated from long range distance by using DTMF signal controlling GSM technique. In this project work i am concentrating on free movement of ground roller operated from the outside of a Hockey ground without any help of human beings. Block diagram of working principles as well as list of primary components are given below.

\section{II.A. Block Diagram With Activities:}

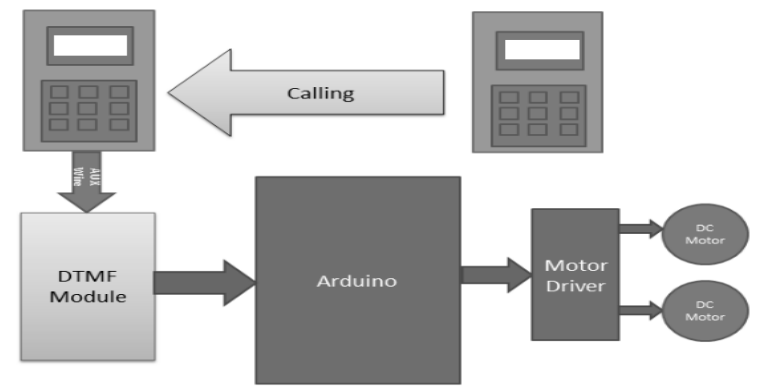

Fig1. DTMF based Arduino Controlled Ground rolling principle 


\section{a) Remote section:}

This section's main component is DTMF. Here we get a tone from our cell phone by using aux wire to DTMF Decoder IC namely MT8870 which decodes the tone into digital signal of 4bit.

\section{b) Control Section:}

Arduino UNO is used for controlling whole the process of robot. Arduino reads commands sent by DTMF Decoder and compare with define code or pattern. If commands are match arduino sends respective command to driver section.

\section{c) Driver section:}

Driver section consists motor driver and two DC motors. Motor driver is used for driving motors because arduino does not supply enough voltage and current to motor. So we add a motor driver circuit to get enough voltage and current for motor. By collecting commands from arduino motor driver drive motor according to commands.

\section{II.B. Formation Of Ground Roller - Primary Componenets :}

A. Dual Tone Multiple Frequency (DTMF) Decoder :

B. Arduino Uno Microcontroller:

C. GSM 900 Module (2 Mobile phone needed,):

D. Motor Driver IC, L293D:

E. Accessories for Roller Body with wheels, chassis, connectors, M-F/M-M jumper.

F. Power supply(Rechargeable Battery).

\section{II.C. Proposed Circuit Diagram:}

Here one motor driver is connected to arduino for driving robot. Motor driver's input pin 2, 7, 10 and 15 is connected at arduino digital pin number 6, 5, 4 and 3 respectively. Here we have used two DC motors to driver robot in which one motor is connected at output pin of motor driver 3 and 6 and another motor is connected at 11 and 14. A 9 volt Battery is also used to power the motor driver for driving motors. A DTMF decoder attached with this circuit and this decoder is plugged into a mobile using an aux wire for receiving command or DTMF Tone. DTMF decoder pin D0-D3 is directly connected with Arduino's pin number $19,18,17,16$. Two 9 Volt batteries are used to power the circuit in which one is used for power the motors, connected at motor driver IC pin number 8 . And another battery is connected to power the remaining circuit.

\section{a) DTMF-ArduinoUNO-Connection:}

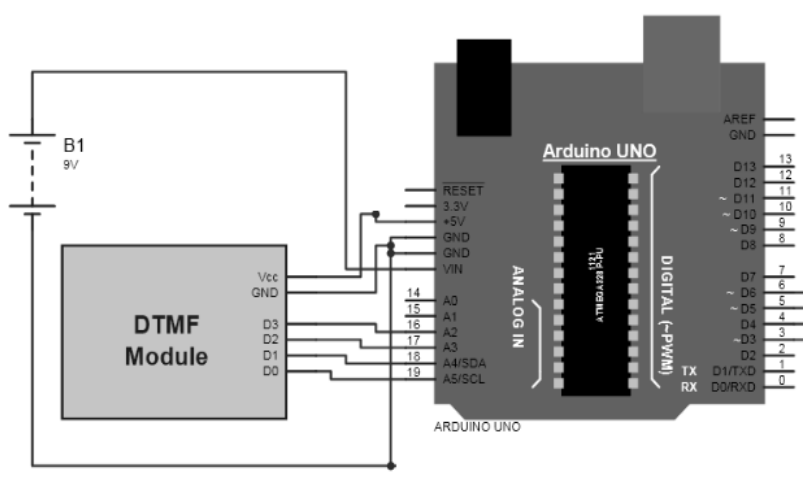

b) Arduino UNO-Motor Driver(L293D) Connection:

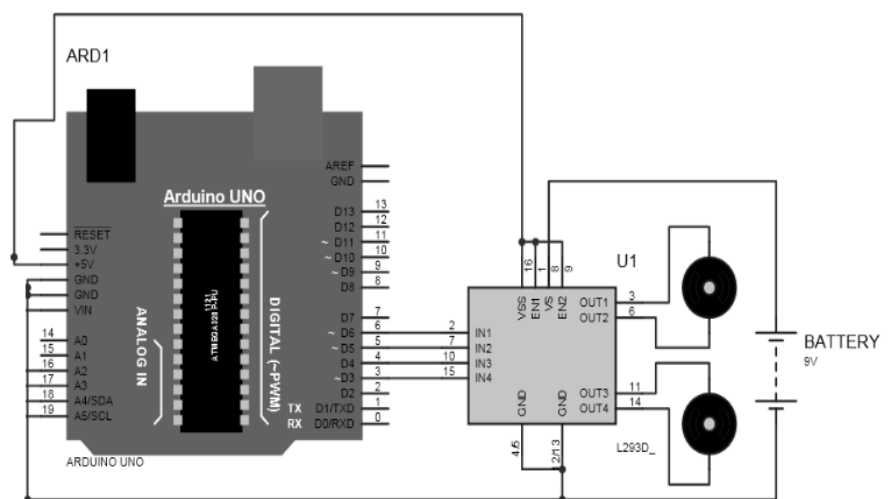


c) Motor Driver(L293D) - Hockey Ground Roller Connection:

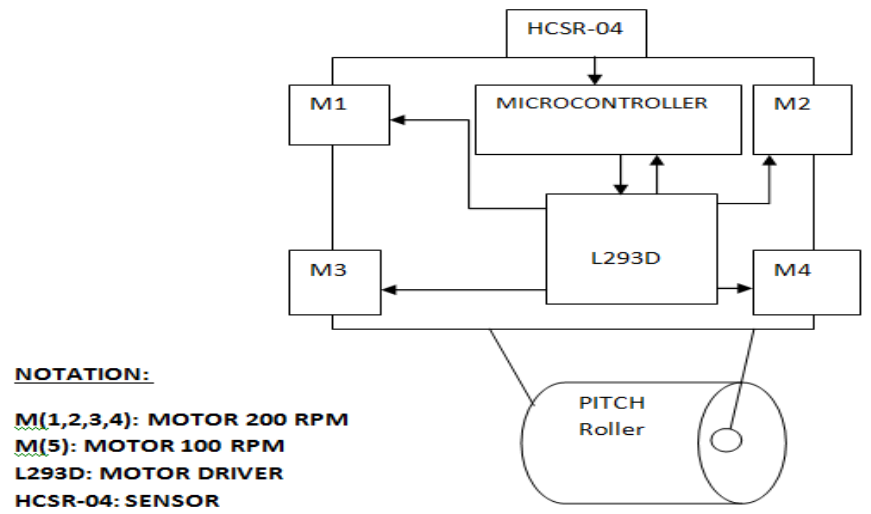

\section{II.D. Roller Operation Procedure:}

STEP-1:

Microcontroller based ground roller can run by some commands that are send via mobile phone. I am using DTMF function of mobile phone. Here I am using the mobile phone to show working of project. One is user mobile phone that i will call 'remote phone' and second one that are connected with Roller's circuit using aux wire. This mobile phone i will call 'Receiver Phone'. First i make a call by using remote phone to receiver phone and then attend the call by manually or automatic answer mode. Now here is how this DTMF controlled ground roller is controlled by cell phone. When i press ' 2 ' by remote phone, roller start to moving forward and moving continues forward until next command comes.

\section{STEP-2:}

When I press ' 8 ' by remote phone, roller change his state and start moving in backward direction until other command comes

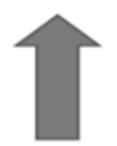

Forward
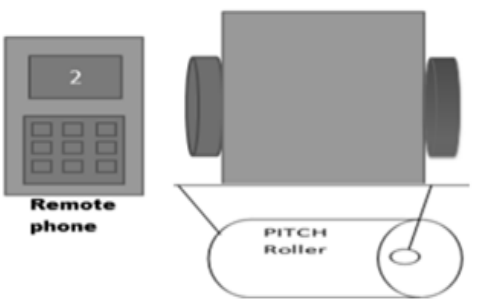

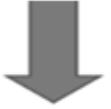

Backward

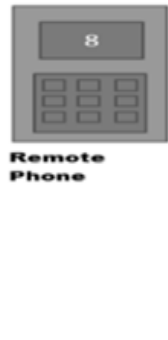

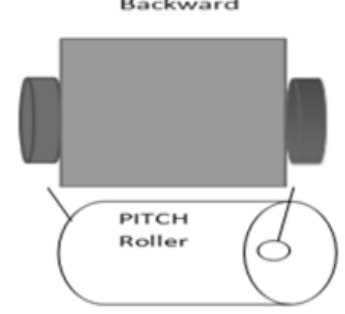

STEP-3:

When i press ' 4 ', Robot get turn left till next command executed. Stopping robot I pass' 5 '. When i press '6', robot turned to right.

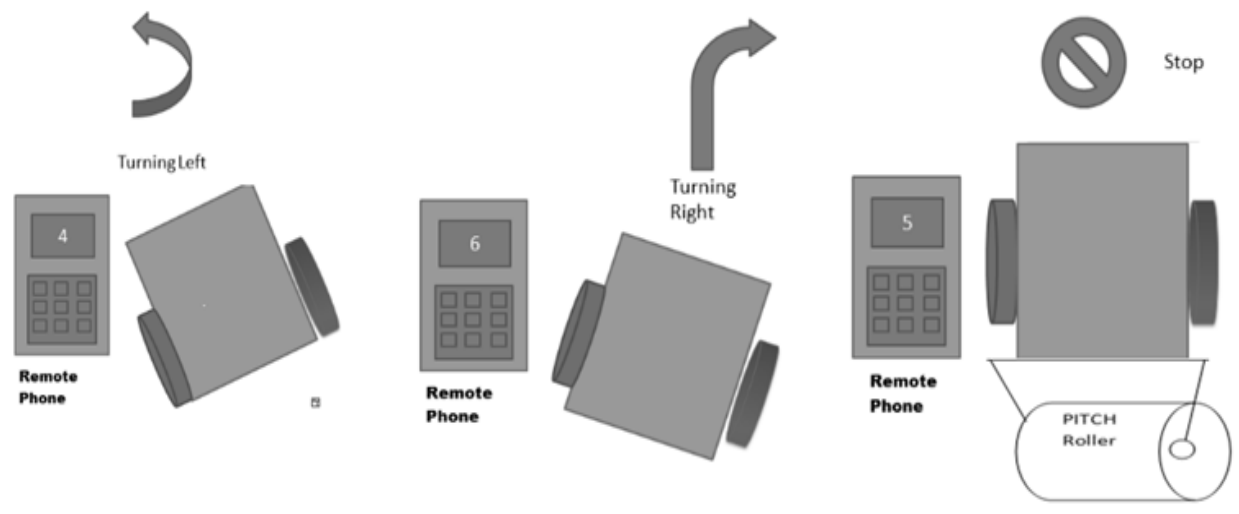


Mobile Phone Operated Dual-tone-multiple-frequency controlled Microcontroller Based Hockey-

II.E. Conditions of DTMF Controlled hockey ground roller:

\begin{tabular}{|c|c|c|c|c|c|c|c|c|c|}
\hline \multicolumn{5}{|l|}{ INPUT } & \multicolumn{5}{|c|}{ OUTPUT } \\
\hline \multirow{2}{*}{$\begin{array}{l}\text { Mobile } \\
\text { Key }\end{array}$} & & & & & & & & & \multirow{2}{*}{$\begin{array}{l}\text { Robot } \\
\text { Movement }\end{array}$} \\
\hline & D3 & D2 & D1 & D0 & M11 & M12 & M21 & M22 & \\
\hline 5 & 0 & 1 & 0 & 1 & 0 & 0 & 0 & 0 & Stop \\
\hline 4 & 0 & 1 & $\mathbf{0}$ & 0 & 1 & 0 & $\mathbf{0}$ & $\mathbf{0}$ & Left \\
\hline 6 & 0 & 1 & 1 & 0 & 0 & 0 & 1 & 0 & Right \\
\hline 2 & 0 & 0 & 1 & 0 & 1 & 0 & 1 & 0 & Forward \\
\hline 8 & 1 & 0 & 0 & 0 & 0 & 1 & 0 & 1 & Backward \\
\hline
\end{tabular}

II.F Proposed Algorithm For Roller Movement With The Help Of Arduino Uno \& Dtmf With The Help Of Mobile Key Pressing:

Step 1:

Set Left most top motor m11 connected with pin 3 of Arduino UNO via pin 15 of Motor driver IC L293D. Set Left most bottom motor m21 connected with pin 5 of Arduino UNO via pin 7 of Motor driver IC L293D. Set Right most top motor m12 connected with pin 4 of Arduino UNO via pin 10 of Motor driver IC L293D.Finally Set Right most bottom motor m22 connected with pin 6 of Arduino UNO via pin 2 of Motor driver IC L293D.

Step 2:

Connect D0 pin of DTMF decoder module with pin 19 of Arduino UNO. Pin 18 of Arduino is connected with D1 pin of DTMF controller. Connect D2 pin of DTMF decoder module with pin 17 of Arduino UNO. Pin 16 of Arduino is connected with D3 pin of DTMF controller.

Step 3: IF [D0 Is equal To 0] AND [D1 Is equal To 1] AND [D2 Is equal To 0] AND [D3 Is equal To 0] CALL FORWARD_MOVEMENT()

Step 4: IF [D0 Is equal To 0] AND [D1 Is equal To 0] AND [D2 Is equal To 0] AND [D3 Is equal To 1] CALL BACKWARD_MOVEMENT()

Step 5: IF [D0 Is equal To 0] AND [D1 Is equal To 0] AND [D2 Is equal To 1] AND [D3 Is equal To 0] CALL LEFT_MOVEMENT()

Step 6: IF [D0 Is equal To 0] AND [D1 Is equal To 1] AND [D2 Is equal To 1] AND [D3 Is equal To 0] CALL RIGHT_MOVEMENT()

Step 7: IF [D0 Is equal To 0] AND [D1 Is equal To 1] AND [D2 Is equal To 1] AND [D3 Is equal To 0] CALL STOP_MOVEMENT()

Step 8:

FORWARD_MOVEMENT(): M11 And M21 Motor rotate [Left most top \& Bottom], M12,M22 Motor rotation stop.

BACKWARD_MOVEMENT(): M12 And M22 Motor rotate [Right most top \& Bottom], M11,M21 Motor rotation stop.

LEFT_MOVEMENT():M11 Motor rotate [Left most top], M12,M21,M22 Motor rotation stop.

RIGHT_MOVEMENT():M21 Motor rotate [Left most bottom], M11,M12,M22 Motor rotation stop.

STOP_MOVEMENT(): M11,M12,M21,M22 Motor rotation stop.

Step 9: IF [ Mobile Key Is Equal To 2] SET D1=1,D0=0,D2=0,D3=0 and goto step 3.

ELSEIF [ Mobile Key Is Equal To 8] SET D1=0,D0=0,D2=0,D3=1 and goto step 4.

ELSEIF [ Mobile Key Is Equal To 4] SET D1=0,D0=0,D2=1,D3=0 and goto step 5.

ELSEIF [ Mobile Key Is Equal To 6] SET D1=1,D0=0,D2=1,D3=0 and goto step 6.

ELSEIF [ Mobile Key Is Equal To 5] SET D1=0,D0=1,D2=1,D3=0 and goto step 7.

\section{Conclussion}

In this proposed work I can successfully generate a technique through which i will take an initiative to remove manual effort of Hockey Grounds man at the time of ground flattering through a roller. This Mobile Phone Operated Dual-tone-multiple-frequency controlled Arduino UNO Microcontroller Based Hockey-ground Rolling Technique reduces manual effort of human beings as well as we can use this technique also in long range communication with the help of DTMF and Mobile GSM network. Even if by pressing mobile key after making a call we can totally control that ground roller from outside the ground.

Journal Papers:

\section{References}

[1]. J. Banuchandar, V. Kaliraj, P. Balasubramanian, S. Deepa, N. Thamilarasi, Automated Unmanned Railway Level Crossing System, International Journal of Modern Engineering Research (IJMER), Vol.2, Issue.1, Jan-Feb 2012 pp-458-463 ISSN: 2249-6645.

[2]. Harshavardhan B.Patil, Prof.V.M.Umale -Arduino Based Wireless Biomedical Parameter Monitoring System Using Zigbee.\| IJETT, Volume 28 Number 7 - October 2015. 
[3]. V. Naga phanindra, B. Suresh Ram -Wireless Remote Control Car Based on ARM7.,International Journal IJETT, Volume 5 Number 5 - Nov 2013.

[4]. Raj Hakani-"DTMF Based Controlled Robot Vehicle", IJSRD - International Journal for Scientific Research \& Development, Vol. 2, Issue 12, 2015,ISSN (online): 2321-0613.

[5]. Awab Fakih, Jovita Serrao, "Cell Phone Operated Robotic Car.”International Journal of Scientific \& Engineering Research, ISSN 2229-5518.

[6]. Yun Chan Cho and Jae Wook Jeon "Remote Robot control System based on DTMF of Mobile Phone", IEEE International Conference INDIN 2008, July 2008.

[7]. Dhiraj Singh Patel1,Dheeraj Mishra,Devendra Pandey,Ankit Sumele,Asst.Prof.Ishwar Rathod,"Mobile Operated Spy Robot",International Journal of Emerging Technology and Advanced Engineering(ISSN 2250-2459 (Online), An ISO 9001:2008 Certified Journal,Volume 3, Special Issue 2, January 2013

Books:

[8]. DSP-base DTMF Decoder",Author-Xiao Meng,PublisherArizona State University, 1996

[9]. Getting Started with Arduino",Massimo Banzi, Publisher:O'Reilly Media,Print: March 2009, Ebook: February 2009,Print ISBN:978-0-596-15551-3,ISBN10:0-596-15551-4,Ebook ISBN:978-0-596-15917-7,ISBN 10:0-596-15917-X

[10]. "Arduino Cookbook",O'Reilly publication,Michael Margolis,ISBN-13: 978-1449313876, ISBN-10: 1449313876 